TITLE:

\title{
Dielectric Properties of Polyethylene Glycols at Microwave Frequencies
}

$\operatorname{AUTHOR}(S):$

Koizumi, Naokazu

\section{CITATION:}

Koizumi, Naokazu. Dielectric Properties of Polyethylene Glycols at Microwave

Frequencies. Bulletin of the Institute for Chemical Research, Kyoto University 1958, 36(4): 105-105

ISSUE DATE:

1958-07-31

URL:

http://hdl.handle.net/2433/75654

RIGHT: 


\title{
ABSTRACTS
}

constant rate of extension $(v)$ depends largely upon viscosity $(\eta)$ and surface tension $(\gamma)$ as well as temperature. Assuming that the apparent relaxation time can be given by a balance between viscosity and surface tension, the spinning condition was derived as follows:

$$
\eta \geq r / v \text {. }
$$

The spinning temperature expected from the above relation showed a good agreement with the experimental results.

\section{Dielectric Properties of Polyethylene Glycols at Microwave Frequencies}

\author{
Naokazu KoIzumI \\ (Gotoh Laboratory) \\ Joumal of Chemical Physics, 27, 625 (1957)
}

The complex dielectric constants of ethylene, diethylene, triethylene, tetraethylene, and hexaethylene glycols in the liquid state have been measured at frequencies of $1.43,9.73$, and $18.7 \mathrm{kmc} / \mathrm{sec}$ at temperatures from 5 to $50^{\circ} \mathrm{C}$. The parameters of dielectric relaxation for these polyethylene glycols have been calculated from the complex dielectric constants and the static dielectric constants by the circular arc rule of Cole and Cole. It has been found that the dielectric relaxation times obtained do not vary much with the homolog of this polyethylene glycol series, being of the order of $10^{-10} \mathrm{sec}$ at $20^{\circ} \mathrm{C}$. The value of relaxation time is the largest for diethylene glycol, decreasing slightly with higher homologs of this series. This striking feature is discussed in terms of flexibility of the polyoxyethylene chain due to internal rotation around the $\mathrm{C}-\mathrm{O}$ bonds of the chain skeleton, which would make more possible a partial and independent orientation of the hydroxyl groups at the ends of the molecular chain in the case of higher polyethylene glycols.

\section{Synthesis of Acetic Acid from Methanol and Carbon Monoxide under High Pressure}

Yosimasa Takezaki, Nobuya Oramoto, Teruhisa Mryazari and Sachio Yuasa (Takezaki Laboratory)

Jounal of the Chemical Society of Japan, Industrial Chemistry Section (Kogyokagaku Zasshi), 60, 1038 (1957)

Kinetic studies were made on the synthesis of acetic acid by the reaction of $\mathrm{CH}_{3} \mathrm{OH} \cdot \mathrm{BF}_{3}$ with carbon monoxide under high pressure, the main course being expressed by

$$
\mathrm{CH}_{3} \mathrm{OH} \cdot \mathrm{BF}_{3}+\mathrm{CO} \longrightarrow \mathrm{CH}_{3} \mathrm{COOH} \cdot \mathrm{BF}_{3}
$$

